\title{
Acute respiratory illness in Adelaide children: breast feeding modifies the effect of passive smoking
}

\author{
Alistair Woodward, Robert M Douglas, Neil M H Graham, Helen Miles
}

\begin{abstract}
Study objective-The aim was to investigate the relation between passive smoking and childhood acute respiratory illness.

Design-The study involved an initial postal survey on a random sample of children followed by a case-control study based on the survey. A respiratory illness score was calculated from maternal reports of episodes of illness in the previous 12 months.
\end{abstract}

Setting-The study was a population survey based on Adelaide metropolitan area in South Australia.

Participants-The reference population $(n=13996)$ was all live born children registered in South Australia in 1983 whose parents lived in Adelaide metropolitan area. Of these, $\mathbf{4 9 8 5}$ families were contacted by post and from 2125 respondents, 1218 (58\%) gave consent for home interview. "Cases" were children with respiratory illness scores in the top $20 \%$, controlling for age and time of year $(n=258)$; "controls" were taken in the bottom $20 \%(n=231)$.

Measurements and main resultsMaternal smoking in the first year of life was associated with a doubling in relative odds of respiratory proneness in the child (odds ratio $=2 \cdot 06,95 \%$ CI 1.25-3.39) after adjustment for confounding by parental history of respiratory illness, other smokers in the home, use of group child care, parent's occupation, and levels of maternal stress and social support. There was no evidence that this association was attributable to differences in the way smoking and non-smoking parents perceived or managed childhood acute respiratory illness. Maternal smoking in the first year, without smoking in pregnancy, was also associated with increased risk of respiratory proneness (odds ratio $1 \cdot 75,95 \%$ CI 1.03-3.0), showing an effect of passive smoking independent of any in utero effect. There was a strong negative effect modification by breast feeding: relative odds of respiratory proneness with maternal smoking were seven times higher among children who were never breast fed than among those who were breast fed.

Conclusions-The results suggest a relatively small but real effect of passive smoking on childhood acute respiratory illness. Effect modification by breast feeding may be due to a combination of behavioural and biological mechanisms.
Acute respiratory illness is the most common cause of morbidity in childhood, world wide, and is a major cause of mortality in many countries. ${ }^{1}$ While most acute respiratory episodes are self limiting, the total cost to parents, children and health services is immense. There may also be important long term sequelae, such as the effects of glue ear on speech development and learning, ${ }^{2}$ and increased susceptibility to illness and diminished respiratory function following lower respiratory illness in infancy. ${ }^{3}$

Investigations of the social and environmental causes of acute respiratory illness have tended to focus on the most severe manifestations of illness, typically episodes of lower respiratory illness leading to admission to hospital. However, patients admitted to hospital form a tiny fraction of all children suffering from acute respiratory illness. ${ }^{4}$

The burden of childhood acute respiratory illness in the community is not spread evenly. Some children are affected rarely, while others are repeatedly ill. ${ }^{5}$ The group at the top end of the frequency distribution tends to be stable over time: not only do children with early lower respiratory illness predominate amongst those who suffer from chest illness in later years, but there is also evidence of "tracking" of rates of less severe respiratory illness. ${ }^{6}$

Passive smoking is a major risk factor for childhood acute respiratory illness. A simple tally of published reports (disregarding variation in the quality of the studies) shows that out of 32 studies published up to June 1988, 22 found that lower respiratory illness was significantly $(p<0.05)$ more common amongst children whose parents smoked. $^{7}$

Of the 10 studies which reported no statistically significant association of parental smoking and childhood acute respiratory illness, only three ${ }^{8-10}$ included children in the $0-2$ years age group. The first two studies cited gave no details of the number of participants in this age range; the other ${ }^{10}$ had low statistical power.

The most plausible non-causal explanations for the association of passive smoking and childhood acute respiratory illness include reporting bias (studies have relied largely on parents' reports of exposure and outcome), differential use of health services, confounding by some aspect of psychosocial stress, and confounding by fetal exposure to smoke products.

The aim of this study was to investigate the relation between passive smoking and childhood acute respiratory infection in children in metropolitan Adelaide, after controlling for these and a wide range of other possible confounding factors. 
Methods

The study took place in two stages: a postal survey conducted in 1985 of a random sample of children whose births were registered in South Australia in 1983; followed by a case-control study based on the survey.

The reference population $(n=13996)$ was all live born children whose births were registered in South Australia in 1983, and whose parents' place of residence as shown on the birth registration form was within the Adelaide metropolitan area (total population 900 000). The Epidemiology Branch of the South Australian Health Commission took a 1-in-2 random sample of these birth registrations. Addresses were deleted if they were inadequate for postal purposes, or if they were within the metropolitan area but relatively inaccessible for interview (being more than 30 minutes drive from the University of Adelaide). Of the remaining 5830 addresses, a randomly selected sample of 5000 was chosen for posting. After further exclusions due to incomplete addresses, a total of 4985 questionnaires were posted.

Initially, names of mothers were included on questionnaires sent out. Following an incident which raised concern over possible breaches in confidentiality it was decided not to use this information with the remainder of the postings. Eighty per cent of the questionnaires were posted to addresses only.

\section{THE SURVEY QUESTIONNAIRE}

The postal questionnaire was based on one which had been used successfully in a previous study in Adelaide, ${ }^{11}$ and was pretested in two pilot studies involving 250 children drawn from the lists of birth registrations in 1980 and 1984 . It consisted of 24 questions in the form of a half A5 size booklet. $^{12}$ The accompanying letter was addressed to the mother by name in the first posting only; otherwise it was headed "To the Householder". The letter included a brief description of the study and an invitation to fill out the questionnaire if the household included a child between the ages of 1 and 3 years.

Parents were asked to provide information on the amount of acute respiratory illness suffered by their child in the previous 12 months, by filling out the question shown in table I. The illnesses listed include a mixture of medical diagnoses and signs and symptoms of acute respiratory illness.

Table I Respiratory illness question, postal survey

Q.1. In the last 12 months, how much did your child suffer from the illnesses listed below? (Please circle your answer).

\begin{tabular}{|c|c|c|c|c|c|}
\hline & 0 bouts & $1-2$ bouts & $3-8$ bouts & $\begin{array}{l}\text { More than } \\
8 \text { bouts }\end{array}$ & $\begin{array}{l}\text { Most of } \\
\text { the time }\end{array}$ \\
\hline Colds & NEVER & RARELY & SOMETIMES & FREQUENTLY & CONSTANTLY \\
\hline Cough & NEVER & RARELY & SOMETIMES & FREQUENTLY & CONSTANTLY \\
\hline Hayfever & NEVER & RARELY & SOMETIMES & FREQUENTLY & CONSTANTLY \\
\hline $\begin{array}{l}\text { Wheeze or } \\
\text { asthma }\end{array}$ & NEVER & RARELY & SOMETIMES & FREQUENTLY & CONSTANTLY \\
\hline Bronchitis & NEVER & RARELY & SOMETIMES & FREQUENTLY & CONSTANTLY \\
\hline Bronchiolitis & NEVER & RAREIY & SOMETIMES & FREQUENTLY & CONSTANTLY \\
\hline Pneumonia & NEVER & RARELY & SOMETIMES & FREQUENTLY & CONSTANTLY \\
\hline Croup & NEVER & RARELY Y & SOMETIMES & FREQUENTLY & CONSTANTLY \\
\hline Sore throat & NEVER & RARELY & SOMETIMES & FREQUENTLY & CONSTANTLY \\
\hline Tonsillitis & NEVER & RARELY & SOMETIMES & FREQUENTLY & CONSTANTLY \\
\hline $\begin{array}{l}\text { Thick nasal } \\
\text { discharge }\end{array}$ & NEVER & RARELY & SOMETIMES & FREQUENTLY & CONSTANTLY \\
\hline Earache & NEVER & RARELY & SOMETIMES & FREQUENTLY & CONSTANTLY \\
\hline $\begin{array}{l}\text { Discharging } \\
\text { ear }\end{array}$ & NEVER & RARELY & SOMETIMES & FREQUENTLY & CONSTANTLY \\
\hline
\end{tabular}

The list aimed to provide as comprehensive a list as possible of the manifestations of acute respiratory illness, in terms which had been found previously ${ }^{11}$ to be understood by most parents.

Questionnaires were sent out between July 1985 and December 1985 in five postings of about 1000 questionnaires each, at intervals of approximately one month. Each posting included addresses of children born in a common 2-3 month period. Reminder postcards were sent to all addresses one week after the first posting, and a further letter and copy of the questionnaire were sent to all addresses from which a response had not been received by three weeks after the initial posting. Of the 4985 questionnaires sent out, 2854 $(57.3 \%)$ were returned completed. Two hundred and thirty six questionnaires were excluded because the children described were born before November 1st 1982 or after December 31 1983, and so were unlikely to have had their births registered in 1983. (In South Australia there is a legal penalty if births are not registered within 60 days.) The survey participants numbered 2618 children, with a mean age of 26 months (range 18 months to 3 years) at the time the questionnaires were completed.

A respiratory illness score was calculated for each participant, based on the responses to the first question in the questionnaire (table I). For each illness listed, a value of 0 was assigned for answers in the first column (indicating the child had "NEVER" suffered this illness in the last 12 months). A value of 1 was assigned for answers of "RARELY", 2 for "SOMETIMES", 3 for "FREQUENTLY", and 4 for answers in the extreme right hand column ("CONSTANTLY"). Values for the 13 illnesses were then summed. Extra points were added if the child suffered at all from pneumonia or asthma ( +2 if either condition recorded, +4 if both conditions recorded). The respiratory score could range from 0 (no illnesses reported) to a theoretical maximum of 56 (representing a child who was reported to be constantly ill with all the listed conditions).

\section{THE CASE-CONTROL STUDY}

The final posting was excluded from interview because it clashed with the Christmas period and summer holidays. Of the 2125 completed questionnaires received from the first four postings, $1218\left(57 \cdot 3^{\circ} \mathrm{o}\right)$ gave consent for home interviews. "Cases" were children whose respiratory score fell within the top $20^{\circ}{ }_{0}$ of scores in the same posting, and "controls" were those children whose respiratory scores were within the bottom $20^{\circ}$ of scores in their posting. Home interviews were carried out with parents of 258 cases and 231 controls by three research nurses. The interview schedule was pretested with 80 parents of children from the 1980 and 1984 birth registration lists.

To investigate the management of children with acute respiratory illness, seven hypothetical case histories were described, and in each case mothers were asked to respond to statements about the best course of action, with either "strongly agree", "agree", "disagree", "strongly disagree" or "don't know". In addition to examining the statements singly, responses were pooled to give an "illness management score", 
which quantified respondents' ability to discern minor from possibly serious acute respiratory illness. This score was devised by selecting for each case history the statement which the investigators judged a priori to provide the clearest test of "appropriate" use of medical services. "Don't know" responses were discarded, other responses were given numerical values of $1-4$, and the total summed to give a score which ranged from 7 ("non-discriminating" use of medical services) to 28 ("discriminating" use), with a median value of 16 . Deletion of "don't know" responses was effectively the same as assigning a score of $\mathbf{0}$ for that statement (no-one replied "don't know" to all statements).

At the end of the interview, mothers were asked to complete a self administered questionnaire which included three components of perceived stress-major life events, minor life events ("daily hassles"), and psychological distress. Major life events in the previous 12 months were assessed using the Life Events Inventory, ${ }^{13}$ with the exclusion of 10 items not relevant to mothers of young children. Minor, irritating, day to day stressful events over the last month were assessed using the Daily Hassles Scale. ${ }^{14}$ Data on materna

Table II Maternal smoking and other factors associated with respiratory proneness

\begin{tabular}{|c|c|c|c|c|}
\hline Risk factor & Prone & Not prone & $\begin{array}{l}\text { Crude } \\
\text { OR }\end{array}$ & {$\left[\begin{array}{lll}95 \% & C I\end{array}\right]$} \\
\hline $\begin{array}{l}\text { Maternal smoking after birth } \\
\text { Yes } \\
\text { No }\end{array}$ & $\begin{array}{l}102 \\
156\end{array}$ & $\begin{array}{r}49 \\
182\end{array}$ & $\begin{array}{l}2.43 \\
1.0\end{array}$ & {$[1.63-3.61]$} \\
\hline $\begin{array}{l}\text { Sex of child } \\
\text { Male } \\
\text { Female }\end{array}$ & $\begin{array}{l}157 \\
101\end{array}$ & $\begin{array}{l}107 \\
124\end{array}$ & $\begin{array}{l}1.80 \\
1.0\end{array}$ & {$[1 \cdot 26-2 \cdot 58]$} \\
\hline $\begin{array}{l}\text { Other children in family } \\
\text { Yes } \\
\text { No }\end{array}$ & $\begin{array}{r}216 \\
42\end{array}$ & $\begin{array}{r}172 \\
59\end{array}$ & $\begin{array}{l}1.76 \\
1.0\end{array}$ & {$[1 \cdot 14-2 \cdot 74]$} \\
\hline $\begin{array}{l}\text { Father's history of } \\
\text { respiratory illness } \\
\text { Yes } \\
\text { No }\end{array}$ & $\begin{array}{r}93 \\
150\end{array}$ & $\begin{array}{r}48 \\
179\end{array}$ & $\begin{array}{l}2 \cdot 31 \\
1.0\end{array}$ & {$[1.54-3.47]$} \\
\hline $\begin{array}{l}\text { Mother's history of } \\
\text { respiratory illness } \\
\text { Yes } \\
\text { No }\end{array}$ & $\begin{array}{l}131 \\
123\end{array}$ & $\begin{array}{r}53 \\
176\end{array}$ & $\begin{array}{l}3.54 \\
1.0\end{array}$ & {$[2 \cdot 41-5 \cdot 20]$} \\
\hline $\begin{array}{l}\text { Use of group child care } \\
\text { Yes } \\
\text { No }\end{array}$ & $\begin{array}{l}116 \\
142\end{array}$ & $\begin{array}{r}61 \\
169\end{array}$ & $\begin{array}{l}2.26 \\
1.0\end{array}$ & {$[1.55-3.31]$} \\
\hline $\begin{array}{l}\text { Occupation } \\
\text { (Congalton grade) } \\
\text { Pensioners } \\
\text { Low }(6,7) \\
\text { Medium }(4,5) \\
\text { High }(1,3)\end{array}$ & $\begin{array}{r}16 \\
64 \\
144 \\
33\end{array}$ & $\begin{array}{r}9 \\
34 \\
136 \\
52\end{array}$ & $\begin{array}{l}2 \cdot 80 \\
2.97 \\
1.67 \\
1.0\end{array}$ & $\begin{array}{l}(1 \cdot 13-6 \cdot 97] \\
{[1 \cdot 63-5 \cdot 39]} \\
{[1 \cdot 02-2 \cdot 73]}\end{array}$ \\
\hline $\begin{array}{l}\text { Mother's education } \\
\text { Low } \\
\text { High }\end{array}$ & $\begin{array}{r}85 \\
173\end{array}$ & $\begin{array}{r}46 \\
185\end{array}$ & $\begin{array}{l}1.98 \\
1.0\end{array}$ & {$[1 \cdot 31-2 \cdot 98]$} \\
\hline $\begin{array}{l}\text { Stress } \\
\text { High } \\
\text { Medium } \\
\text { Low }\end{array}$ & $\begin{array}{r}88 \\
126 \\
42\end{array}$ & $\begin{array}{r}33 \\
116 \\
72\end{array}$ & $\begin{array}{l}3.96 \\
1.91 \\
1.0\end{array}$ & $\begin{array}{l}{[2 \cdot 31-6 \cdot 78]} \\
{[1 \cdot 21-3 \cdot 02]}\end{array}$ \\
\hline $\begin{array}{l}\text { Social support } \\
\text { Low } \\
\text { High }\end{array}$ & $\begin{array}{l}121 \\
131\end{array}$ & $\begin{array}{r}97 \\
125\end{array}$ & $\begin{array}{l}1.19 \\
1.0\end{array}$ & {$[0 \cdot 83-1 \cdot 71]$} \\
\hline $\begin{array}{l}\text { Breast feeding } \\
\text { Yes } \\
\text { No }\end{array}$ & $\begin{array}{r}209 \\
49\end{array}$ & $\begin{array}{r}208 \\
23\end{array}$ & $\begin{array}{l}0.47 \\
1.0\end{array}$ & {$[0 \cdot 28-0 \cdot 80]$} \\
\hline $\begin{array}{l}\text { Other smokers at home } \\
\text { Yes } \\
\text { No }\end{array}$ & $\begin{array}{l}104 \\
154\end{array}$ & $\begin{array}{r}81 \\
150\end{array}$ & $\begin{array}{l}1.25 \\
1.0\end{array}$ & {$[0 \cdot 87-1 \cdot 81]$} \\
\hline $\begin{array}{l}\text { Use of health services } \\
\text { Non-discriminating } \\
\text { Discriminating }\end{array}$ & $\begin{array}{l}145 \\
113\end{array}$ & $\begin{array}{r}90 \\
141\end{array}$ & $\begin{array}{l}2.01 \\
1.0\end{array}$ & {$[1 \cdot 40-2 \cdot 88]$} \\
\hline
\end{tabular}

$\overline{\mathrm{OR}}=$ odds ratio; $\mathrm{CI}=$ confidence interval psychological distress, also from the preceding one month, were collected via the 12 item version of the General Health Questionnaire. ${ }^{15}$ Women who scored above the medians for all three stress measures were defined as the "high" stress group, while those scoring below the medians for all three measures were defined as the "low" stress group. The remainder were defined as experiencing moderate stress. The median scores were Life Events Inventory 23 (range 0-216), Daily Hassles Scale 9 (range 0-64), and General Health Questionnaire 1 (range 0-12). Questionnaire data were collected also on maternal social supports, using a modified form of the Maternal Social Support Index. ${ }^{16}$ Seven aspects of social support were scored, then summed to give a global index (range 0-19, median 13). "Poor" support was defined as scoring below the median, "good" support as a score above the median.

\section{DATA ANALYSIS}

Statistical analysis was by conventional bivariate techniques included on SPSS-X, and the logistic regression package in SYSTAT. Confidence limits on odds ratios were calculated using the test based method described by Breslow and Day. ${ }^{17}$ Confounding and effect modification were explored using the approach recommended by Rothman $^{18}$ : firstly, calculation of stratified risk estimates and comparison of crude and adjusted odds ratios (calculated by the Mantel-Haenszel method) ${ }^{19}$ and secondly, multivariate analysis by logistic regression. Adjusted risk estimates were calculated from coefficients in the logistic model, in the conventional fashion.

\section{Results}

The proportion of questionnaires returned and eligible for this study was $2618 / 4989(52.5 \%)$. On the basis of the first posting, which was addressed to named individuals, we estimate that approximately $29 \%$ of families never received the questionnaire, as they had moved since the birth of their child.

The distribution of the respiratory scores calculated from survey questionnaires is shown in the figure. The reliability of the score was tested by asking again at interview about children's respiratory illnesses in the previous 12 months, and calculating a second respiratory score in the

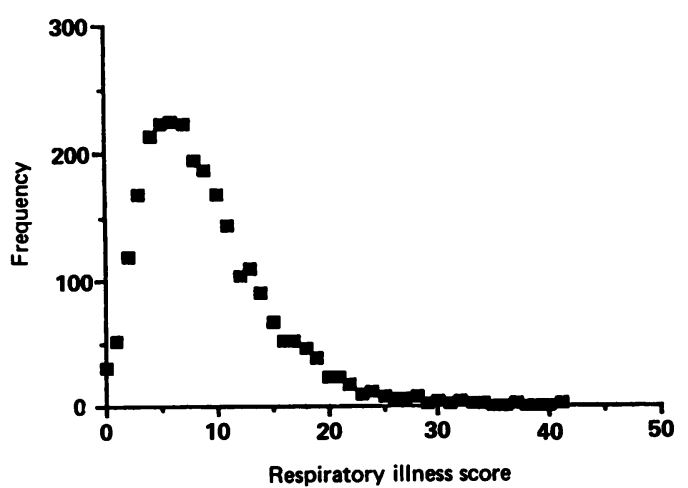

Frequency distribution of respiratory illness score 
same manner as the score calculated from the mailed questionnaires. There was virtually no overlap of study groups on retest: fewer than $1 \%$ (4/489) of children in the "not prone" group had scores on retesting which were in the "prone" range, or vice versa.

The proportions of women who reported smoking during pregnancy and in the first 12 months after birth were $23.6 \%$ and $27 \cdot 7 \%$. Women included in the interview study were asked the same questions a second time, at interview. Only $11 / 487(2.3 \%)$ of mothers gave inconsistent information concerning smoking in the first 12 months after birth, as did $9 / 487(1.8 \%)$ concerning smoking in pregnancy.

Table II shows the relation of maternal smoking to respiratory proneness. In this table "breast fed" includes all children ever breast fed. A history of respiratory illness for the mother or father was recorded if the parent reported that they had ever been treated by a doctor for asthma, bronchitis or emphysema. Group child care was defined as current use of a child care centre or creche, excluding family day care, occasional home care or play groups. Occupation was the reported usual occupation of the chief income earner in the household, coded using the Congalton seven point scale. ${ }^{20}$ (Those retired or

Table III Passive smoking and respiratory proneness, by breast feeding

\begin{tabular}{lcccc}
\hline & Prone & Not prone & Odds ratio & {$\left[95^{\circ}{ }_{0} \mathrm{CI}\right]$} \\
\hline BREAST FED & & & & \\
Maternal smoking after birth & 71 & 46 & 1.81 & {$[1 \cdot 18-2 \cdot 79]$} \\
Yes & 138 & 162 & & \\
No & & & & \\
NOT BREAST FED & 31 & 3 & 11.5 & {$[3 \cdot 4-38 \cdot 5]$} \\
Maternal smoking after birth & 18 & 20 & & \\
Yes & 18 & & & \\
No & &
\end{tabular}

Table IV Risk factors for respiratory proneness. Results of logistic regression

\begin{tabular}{|c|c|c|c|c|}
\hline \multirow{2}{*}{$\begin{array}{l}\text { Variable } \\
\text { Maternal smoking in first year }\end{array}$} & \multicolumn{2}{|c|}{$\begin{array}{l}\text { Coefficient } \\
(+S E)\end{array}$} & \multirow{2}{*}{$\begin{array}{l}\begin{array}{l}\text { Adjusted } \\
\text { odds ratio }\end{array} \\
2.06\end{array}$} & \multirow{2}{*}{$\frac{\left[95^{\circ}{ }_{0} \mathrm{CI}\right]}{[1 \cdot 25-3 \cdot 39]}$} \\
\hline & 0.721 & $(+0.255)$ & & \\
\hline Sex (male) & 0.656 & $(+0.215)$ & 1.93 & {$[1 \cdot 27-2 \cdot 93]$} \\
\hline No siblings & 0.218 & $(+0 \cdot 112)$ & $1 \cdot 24^{\star}$ & {$[1.00-1.55]$} \\
\hline $\begin{array}{l}\text { Father's history of respiratory } \\
\text { illness }\end{array}$ & 0.519 & $(+0.239)$ & 1.68 & {$[1 \cdot 05-2 \cdot 69]$} \\
\hline $\begin{array}{l}\text { Mother's history of respiratory } \\
\text { illness }\end{array}$ & $0 \cdot 787$ & $(+0 \cdot 229)$ & $2 \cdot 20$ & {$[1 \cdot 40-3 \cdot 44]$} \\
\hline Child care (use of) & 0.798 & $(+0.227)$ & $2 \cdot 22$ & {$[1 \cdot 42-3 \cdot 47]$} \\
\hline $\begin{array}{l}\text { Occupation } \\
\text { High (Congalton 1-3) } \\
\text { Medium (Cong. 4,5) } \\
\text { Low (Cong. 6,7) } \\
\text { Pensioner }\end{array}$ & $\begin{array}{l}0 \cdot 446 \\
0 \cdot 707 \\
0 \cdot 394\end{array}$ & $\begin{array}{l}(+0.290) \\
(+0364) \\
(+0.594)\end{array}$ & $\begin{array}{l}1 \cdot 0 \\
1 \cdot 56 \\
2 \cdot 03 \\
1 \cdot 48\end{array}$ & $\begin{array}{l}{[0 \cdot 88-2 \cdot 75]} \\
{[0 \cdot 99-4 \cdot 14]} \\
{[0 \cdot 46-4 \cdot 75]}\end{array}$ \\
\hline $\begin{array}{l}\text { Stress } \\
\text { Low } \\
\text { Moderate } \\
\text { High }\end{array}$ & $\begin{array}{l}0.711 \\
0.962\end{array}$ & $\begin{array}{l}(+0.276) \\
(+0.328)\end{array}$ & $\begin{array}{l}1 \cdot 0 \\
2 \cdot 03 \\
2 \cdot 61\end{array}$ & $\begin{array}{l}{[1 \cdot 19-3 \cdot 49]} \\
{[1 \cdot 37-4 \cdot 98]}\end{array}$ \\
\hline Social support (low) & $0 \cdot 169$ & $(+0 \cdot 229)$ & 0.85 & {$[0.53-1 \cdot 32]$} \\
\hline Breast fed (never) & 0.493 & $(+0 \cdot 316)$ & 1.64 & {$[0 \cdot 88-3 \cdot 04]$} \\
\hline Other smokers at home $(\geqslant 1)$ & $0 \cdot 302$ & $(+0.239)$ & 0.73 & {$[0 \cdot 46-1 \cdot 18]$} \\
\hline Illness management score & $0 \cdot 107$ & $(+0.028)$ & $0.90 t$ & {$[0.85-0.95]$} \\
\hline
\end{tabular}

presently unemployed were asked to report their previous occupation, and were coded by this occupation.) The level of mother's education was described as "low" if the mother reported fewer than four years post-primary schooling, and "high" with four or more years. Mothers were described as "discriminating" in use of health services for childhood acute respiratory illness if they scored above the median for the illness management score, and "non-discriminating" if they scored below the median for this score.

There was no evidence in the stratified analyses of effect modification, with the exception of breast feeding (table III). To determine whether the apparent protective effect of breast feeding in the presence of maternal smoking was related to duration of breast feeding, children in the "ever breast fed" category were divided into those breast fed for $\leqslant 6$ months, and those breast fed for $>6$ months. Amongst children breast fed for $\leqslant 6$ months $(n=194)$, the relative odds of proneness due to maternal smoking were $3.0\left(95^{\circ}{ }_{0} \mathrm{CI}\right.$ 1.6-5.4). Amongst children breast fed for $>6$ months $(n=223)$, the relative odds of proneness associated with maternal smoking were $0.8\left(95^{\circ} \mathrm{o}\right.$ CI 0.4-1.7)

Independent variables included in a multiple logistic regression model were the major predictor variables from the bivariate analyses, and stress, social support, breast feeding, other smokers at home and the illness management score. With the exception of the illness management score and number of siblings, all variables were treated in the analysis as categorical variables. No interaction terms were included in the first model (results shown in table IV).

To test whether effect modification by breast feeding was due to unequal distribution of confounding variables between breast feeding categories, the logistic regression model was run separately for breast fed and never breast fed infants. All potential confounders shown in table IV were included. In the never breast fed group, the adjusted odds ratio for maternal smoking in the first year was $28.7\left(95^{\circ}{ }_{o}\right.$ CI 3.67-224.5). In the breast fed group, the adjusted odds ratio was 1.51 (95\% CI 0.87-2.60).

The logistic regression analysis was repeated, including a first order interaction term: maternal

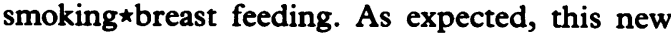
model provided a better fit to the data $\left(\chi^{2}\right.$ on difference in $\log$ likelihood estimates $=18.4$, $\mathrm{DF}=1, \mathrm{p} \ll 0.01)$. The odds ratio for maternal smoking versus no smoking was again found to be strongly influenced by breast feeding status (never breast fed, odds ratio $=13.15\left[95^{\circ}{ }_{0} \mathrm{CI}\right.$ 2.05-78.35]; breast fed, odds ratio 1.51 [ $95^{\circ}{ }_{\mathrm{o}} \mathrm{CI}$ $0 \cdot 88-2.58]$ ). Conversely, the odds ratio of respiratory proneness for never breast fed compared with breast fed was 7.02 where the mother smoked, and 0.81 were the mother did not smoke (this last odds ratio did not differ significantly from 1).

\section{Discussion}

In this study information on both children's respiratory illnesses and parental smoking was obtained by questionnaire. It is difficult to test formally the validity of the responses to the 
respiratory illness questionnaire, as parents' reporting provides practically the only means of learning about episodes of acute respiratory illness which are never referred to health services. The information obtained in this study may be imprecise at the level of individuals, as mothers were required to interpret illnesses and symptoms in their own way, and to recall events over a 12 month period. However, the focus of the study was differences between groups, rather than individuals, and the groups were chosen to represent the extremes of the range of respiratory illness. The distance between the groups in terms of reported symptoms and health service use was considerable. (For example, $21.8 \%$ of the prone group had been admitted to hospital with lower respiratory illness in the first 18 months of life, compared with only $1.3 \%$ of the not prone group.) The interview results showed that the questionnaire was highly reliable as a means of distinguishing the study groups.

There are two sources of uncertainty affecting the estimates of childhood passive smoking used in this study. These are factors other than parental smoking which influence a child's exposure to environmental tobacco smoke, and the inaccuracies of self reported parental smoking. The first set of factors was not investigated here. A comparison of self reported maternal smoking with cotinine levels in stored serum taken in midpregnancy (unpublished data) indicated that underreporting of smoking during pregnancy was not common-amongst those tested only $9 \%$ of self reported non-smokers had serum cotinine levels indicating likely active smoking (that is, $\geqslant$ $57 \mathrm{nmol} /$ litre). ${ }^{21}$ The self reported smoking data were reliable-when questions about presence or absence of smoking were asked a second time at the interview, $98 \%$ of mothers gave consistent responses.

It has been suggested ${ }^{22}$ that parents' respiratory illnesses may act as intermediate factors (since parents who smoke suffer more respiratory tract infections, which may be passed on to children). However there was no sign of this in our study. In stratified analyses the strength of the association between maternal smoking and respiratory proneness did not vary substantially or consistently with mother's or father's history of respiratory illness. Consequently, in the multivariate analysis mother's and father's history of respiratory illness were included as potential confounders.

With the measures used in this study, there was no evidence that the association of maternal smoking and childhood acute respiratory illness can be attributed to differences in the way parents use health services to care for children with respiratory illnesses. It must be noted that there are shortcomings in the measures used. First, without prospective information it is not possible to determine whether mothers' knowledge and attitudes concerning acute respiratory illness are a result or a cause of children's respiratory proneness. Second, it is not always certain what constitutes "appropriate" use of health services. Doctors themselves often disagree on clinical criteria and assessment of particular cases (this was clearly evident when a sample of general practitioners were tested on the cases used in this study [unpublished data]). Moreover, the "appropriate" course of action in dealing with an ill child depends not only on the clinical setting, but also on family circumstances (such as availability of alternative sources of advice and support).

The measures of psychosocial stress used in the study were strongly associated with respiratory proneness, but did not confound the association of maternal smoking and proneness. The relation of stress and social supports to childhood acute respiratory illness in this study will be examined in detail in another paper.

There was no means of directly obtaining information on households which did not respond to the study questionnaire. Aggregated data obtained from the South Australian Health Commission for all births in 1983 with parents resident in the study area showed that children with working class parents were slightly underrepresented in the survey but the maternal age and birthweight profiles were similar. While differential response to the questionnaire may bias survey descriptors such as social class, it is unlikely in our opinion to bias the association observed between passive smoking and childhood acute respiratory illness.

Reporting bias would influence the results of the study if mothers who smoked systematically overreported respiratory illnesses amongst their children, when compared with non-smokers. There are no obvious reasons why this should be so. Within proneness categories, mothers who smoked had lower illness management scores than non-smokers. This is consistent with the proposition that smokers tend on balance to "overdiagnose" and "overuse" medical services for children with acute respiratory illness. The observation that the rates of admission to hospital for conditions other than acute respiratory illness were higher among smokers (unadjusted odds ratio $=1 \cdot 27,95 \%$ CI 1.10-1.62) might also indicate a greater propensity for smokers to report children's illnesses in general. However, if such a bias did exist, it would be expected to have a much greater effect on reported symptoms and illnesses than on reported hospital admissions, yet the associations of maternal smoking with respiratory proneness and with admission to hospital with lower respiratory illness in the first 18 months of life were similar.

The strength of the association was moderate only (representing an approximate twofold increase in risk), but consistent with the findings of other studies which used symptom based outcomes. ${ }^{2324}$ The association was not specific for any particular respiratory complaint. In the postal survey data set, children whose mothers smoked in the first year after birth suffered more upper respiratory illness, more lower respiratory illness, and more ear illness. The only respiratory complaints which were not significantly associated (at $p=0.05$ ) with maternal smoking were hayfever (odds ratio $=0.80,95 \%$ CI $0.62-$ 1.03), pneumonia (odds ratio $=1.23,95 \%$ CI $0.67-2 \cdot 28$ ), and croup (odds ratio $=0.92,95^{\circ}{ }_{0} \mathrm{CI}$ $0 \cdot 74-1 \cdot 13$ ). The lack of an association of maternal smoking with particular respiratory complaints does not weigh heavily against a causal explanation. It seems quite plausible, in view of 
what is known about the toxicology and transmission of tobacco smoke, that passive smoking could play a part in initiating or aggravating conditions throughout the respiratory tract.

Of the 2607 respondents to the postal survey who gave full information on smoking, 580 $(22.2 \%)$ reported they had smoked during both pregnancy and the first year after birth, 143 $(5.4 \%)$ reported smoking in the first year but not in pregnancy, and $36(1.4 \%)$ reported smoking in pregnancy but not in the first year after birth. In this data set, the odds ratio for proneness with maternal smoking was substantially reduced when adjusted for smoking in pregnancy (adjusted odds ratio $=1 \cdot 25,95^{\circ} \%$ CI $0 \cdot 95-1 \cdot 64$ ). However, this analysis may represent "overcontrolling", as maternal smoking in pregnancy is very strongly correlated with maternal smoking in the postnatal period. If the effect of postnatal smoking on respiratory proneness was entirely attributable to smoking in pregnancy (as suggested by Taylor and Wadsworth ${ }^{25}$ ), one would expect no increase in risk of proneness amongst children of mothers who did not smoke in pregnancy, but did smoke postnatally. In fact there was an increase in risk in this group, when compared with children whose mothers had never smoked (odds ratio $=1.75$, 95\% CI 1.03-3.00).

On the basis of these findings, the association of respiratory proneness and maternal smoking in the first 12 months after birth cannot be entirely attributed to the effects of maternal smoking in pregnancy. Smoking in pregnancy may have an independent effect on susceptibility to acute respiratory illness in childhood. Such an effect is plausible considering the toxic effects of nicotine and tobacco smoke observed in animal studies, ${ }^{26}$ but it will remain difficult to quantify precisely such an effect in humans while mothers' smoking in pregnancy is strongly correlated with smoking habit after the birth.

In this study population children who were breast fed suffered less respiratory illness than those children who were only ever bottle fed, but the difference was reduced, and no longer statistically significant $(p>0.05)$, when the analysis was adjusted for confounding factors. Breast feeding modified the effect of maternal smoking, to decrease the risk of acute respiratory illness. When children who had never been breast fed were compared with children who had been breast fed, the relative odds of proneness associated with maternal smoking (adjusted for confounders) were reduced from 13.2 to $1 \cdot 5$. The number of children in the never breast fed group was small, leading to wide confidence intervals around the relative odds estimates. However, evidence of effect modification was still present when larger numbers were included in analysis, and children were grouped by duration of breast feeding. The risk of respiratory proneness associated with maternal smoking diminished with increasing duration of breast feeding. Amongst children breast fed for more than 6 months, there was no increase in risk of respiratory proneness associated with maternal smoking.

One possible explanation for this effect modification is that breast feeding is associated with reduced exposure of the infant to smoke, when compared with infants who are bottle fed. This could result from a reduction in the total amount smoked by the mother, or in the amount smoked around the infant. There is evidence that women who smoke are less likely to breast feed, ${ }^{27}$ and if they do begin, tend to cease breast feeding earlier than women who do not smoke. ${ }^{28}$ Nicotine has been shown in laboratory studies to inhibit prolactin release. ${ }^{29}$ Therefore, amongst mothers who smoke, those who are breast feeding may tend to smoke less than those who are not breast feeding. Such a difference was present in this study population, but when the population of mothers who smoked was stratified by amount smoked, respiratory proneness remained less common amongst breast fed than bottle fed infants. This indicates a modifying effect of breast feeding on risk of proneness due to maternal smoking, independent of an association of breast feeding with lower smoking rates.

Do mothers who breast feed smoke less around their child? We obtained no information in this study on the smoking "hygiene" of parents. In another study ${ }^{30}$ we noted a tendency of breast feeding mothers to smoke less around their children than did mothers who were bottle feeding. However, the numbers in the subgroups were small, so were the differences between the two groups, and adjustment for socioeconomic status reduced the differences further.

What biological mechanisms might explain the modified effect of passive smoking due to breast feeding? The anti-infective constituents of breast milk are well known. While these constituents could not directly counteract the effects of tobacco smoke on the respiratory tract, it may be that breast feeding tends to tip the balance in favour of the host, by strengthening specific and non-specific immune defences. ${ }^{31}$ This protective effect may not be evident when the risk of acute respiratory illness is low, but becomes apparent when the risk of illness increases, due to adverse environmental influences such as crowding, poor hygiene, or tobacco smoke. Similar effect modification has been reported with other infectious diseases: for example, a study ${ }^{32}$ of child mortality in Malaysia found protection against diarrhoeal diseases by breast feeding was strongest where piped water and/or toilet sanitation were not available.

The anti-infective constituents of breast milk boost passive immunity only, and do not directly provide protection much beyond the time that breast feeding ceases. However, it may be that the most important effect of breast feeding is to postpone the age at which infection and illness first occur. There is an association between lower respiratory illness in the first year of life and long lasting increased risk of severe respiratory illness. $^{33}$ If respiratory proneness is indeed determined by the age of 6 or 12 months, then the balance of adverse and favourable factors during that critical early period will have effects throughout childhood, and maybe beyond.

We have found one other published paper ${ }^{34}$ which reports on the modified effect of passive smoking, in relation to childhood acute respiratory illness, with breast feeding. In this 
cross section study of 18 month old children in Shanghai, the relative risk of hospital admission for respiratory illness in heavy smoking households ( $20+$ cigarettes per day) compared with non-smoking households was 1.55 (breast fed children), and 2.96 (artificially fed children). In the Shanghai population the effect modification cannot be explained by a relation between maternal smoking and breast feeding, since none of the mothers smoked. Children's exposure to smoke was due entirely to smoking by other household members than the mother. In these circumstances, the explanation is likely to be a biological protective effect of breast milk against the irritation of smoke in the respiratory tract. Further research is needed to elucidate the mechanisms of such an action.

We wish to thank Dr Philip Ryan for statistical advice, Ms Lorraine Davies, Ms Bernadette Roberts, and Ms Kim Boatwright for interviewing, and Professor Tony McMichael for advice on research design and critical comments on drafts of this paper.

1 Leowski J. Mortality from acute respiratory infections in children under 5 years of age: global estimates. World children under 5 years of age:
Health Stat $Q 1986 ; 39: 138-44$.

2 Paradise JL. Otitis media in infants and children. Pediatrics 1980; 65: 917-43.

3 Mok JYQ, Simpson H. Oucome for acute bronchitis, bronchiolitis and pneumonia in infancy. Arch Dis Child 1984; 59: 306-9.

4 Denny FW, Clyde WA. Acute lower respiratory tract infections in nonhospitalized children. $\mathcal{J}$ Pediatr 1986; 108 635-46.

5 Court SDM. Epidemiology and natural history of respiratory infections in children $\mathcal{f}$ Clin Pathol 1968; 21 (suppl 2): $30-4$

6 Pinnock CB, Douglas RM, Badcock NR. Vitamin A status in children who are prone to respiratory tract infections. Aust Pediatr F 1986; 22: 95-9.

7 Woodward A. Passive smoking and acute respiratory illness in childhoood. Unpublished Ph.D. thesis, University of childhoood. Un.

8 Lebowits MD, Burrows B. Respiratory symptoms related to smoking habits of family adults. Chest $1976 ; 69: 48-50$.

9 Love GJ, Lan S, Shy CM, Struba RJ. The incidence and severity of acute respiratory illness in families exposed to different levels of air pollution, New York metropolitan area, 1971-2. Arch Environ Health 1981; 36: 66-73.

10 Gardner G, Frank AL, Taber L. Effects of social and family factors on viral respiratory infection and illness in the firs year of life. $\mathcal{F}$ Epidemiol Community Health 1984; 38: 42-8.

11 Douglas RM, Miles HB. Vaccination against streptococcus pneumoniae in childhood: lack of demonstrable benefit in young Australian children. $\mathcal{F}$ Infect Dis 1984; 149: 861-9.
12 Dillman DA. Mail and telephone surveys. The Total Design Method. New York: Wiley, 1978.

13 Tennant C, Andrews G. A scale to measure the stress of life events. Aust NZ F Psychiatry 1976; 10: 27-32.

14 Kanner AD, Coyne JC, Schaefer Cet al. Comparisons of two modes of stress measurement: daily hassle and uplifts versus major life events. $₹$ Behav Med 1981; 4: 1-39.

15 Goldberg DP. The detection of psychiatric illness by questionnaire. London: Oxford University Press, 1972.

16 Pascoe JM, Walsh-Clifford N, Earp JA. Construct validity of a maternal social support scale. $\mathcal{F}$ Develop Behav Pediat 1982; 3: 122

17 Breslow NE, Day NE. Statistical methods in cancer research. Volume 1-The analysis of case-control studies. Lyon: International Agency for Research on Cancer, 1980.

18 Rothman KJ. Modern epidemiology. Boston: Little, Brown 1986.

19 Mantel N, Haenszel W. Statistical aspects of the analysis of data from retrospective studies of disease. $f$ Natl Cancer Inst 1959; 22: 719-48.

20 Congalton AA. Status and power in Australia. Melbourne: Cheshire Press, 1969.

21 Sepkovic DW, Haley NJ, Hoffman D. Elimination from the body of tobacco products by smokers and passive smokers. fAMA 1986; 256: 863 .

22 National Research Council Committee on Passive Smoking. Environmental tobacco smoke. Measuring exposures and assessing health effects. National Research Council, Board on Environmental Studies and Toxicology. Washington DC: National Academy Press, 1986.

23 Fergusson DM, Horwood LJ, Taylor B. Parental smoking and lower respiratory illness in the first three years of life. $\mathcal{f}$ Epidemiol Community Health 1981; 35: 180-4.

24 Ferris BG, Ware JH, Berkey CS et al. Effects of passive smoking on health of children. Env Health Perspect 1985; 62: $289-95$.

25 Taylor B, Wadsworth J. Maternal smoking during pregnancy and lower respiratory trace illness early in life. Arch Dis Child; 1987; 62: 786-9.

26 Wang NS, Schraufnagel DE, Chen MF. The effect of maternal and oral intake of nicotine on the growth and maturation of fetal and baby mouse lungs. Lung 1983; 161: 27-38.

27 Meyer MB. Breast feeding and smoking. Lancet 1979; i

28 Woodward A, Hand K. Smoking and reduced duration of breast-feeding [Letter]. Med $\mathcal{F}$ Aust 1988; 148: 477-8.

29 Anderson AN, Lund-Andersen C, Falck Larsen J et al. Suppressed prolactin but normal neurophysin level in cigarette smoking breast feeding women. Clin Endocrinol (Oxford) 1982; 17: 363-8.

30 Woodward A, Grgurinovich N, Ryan P. Breast feeding and smoking hygiene: major influences on cotinine in urine of smokers' infants. $\mathcal{F}$ Epidemiol Community Health 1986; 40 : 309-316.

31 Butler JE. Immunologic aspects of breast-feeding, antiinfectious activity of breast milk. Semin Perinatol 1979; 3 255-70.

32 Butz WP, DaVanzo J, Habicht JP. How biological and behavioural influences on mortality in Malaysia vary
during the first year of life. Population Studies 1982; 37: during the

33 Woolcock AJ, Peat JK. The relationship between acute respiratory infections and chronic respiratory disease. In Douglas RM, Kerby-Eaton E. Acute respiratory infections in childhood. Adelaide, South Australia: University of Adelaide; 1985: 21-9.

34 Chen Y, Li W, Yu S, Qian W. Chang-Ning epidemiological study of children's health: I: Passive smoking and children's respiratory diseases. Int $\mathcal{f}$ Epidemiol 1988; 17 348-55. 